\title{
e-Revista Internacional de la Protección Social
}

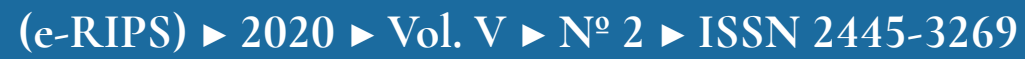

https://editorial.us.es/es/revistas/e-revista-internacional-de-la-proteccion-social

https://dx.doi.org/10.12795/e-RIPS > @ Editorial Universidad de Sevilla 2020

@ळ@ఠ CC BY-NC-ND 4.0.

\section{Recensión de la obra de}

\section{Miguel Ángel Chamocho Cantudo: La regulación jurídica del Trabajo en las Indias Occidentales (1492- 1580), Premio Eduardo de Hinojosa y Naveros en Ciencias Jurídicas 2020, Dykinson, Madrid, 2020}

\author{
Cristina Sánchez-Rodas Navarro \\ Catedrática de Derecho del Trabajo y de la Seguridad Social \\ Universidad de Sevilla \\ csrodas@us.es@0000-0001-9780-7860
}

Recibido: 17.12 .2020 | Aceptado: 17.12.2020

Los laboralistas hemos comenzado, tradicionalmente, a construir la especificidad de las raíces históricas de nuestro sector del ordenamiento jurídico, el Derecho del Trabajo, a partir de la revolución industrial, con la emergencia, primero de un derecho social, luego obrero y finalmente del trabajo, ya en pleno siglo XX. Sin embargo, somos conscientes que las relaciones de trabajo, siempre amparadas bajo un marco jurídico, existen desde que en la humanidad, en el desarrollo de su convivencia social, unos necesitan ofrecer su fuerza de trabajo a terceros a cambio de un salario. Ahora bien, la doctrina laboralista no ha prestado suficiente atención hasta la fecha por esas relaciones jurídicas de trabajo anteriores al siglo XIX, entendiendo que, al estar amparadas en el sector del ordenamiento jurídico privado, y reguladas bajo una modalidad contractual, el arrendamiento de servicios, eran unos precedentes excesivamente remotos al naciente sector del Derecho del Trabajo y, de su ámbito contractual, el contrato de trabajo, naciente en España ya en el siglo XX.

La lectura de este libro nos muestra, sin perjuicio de estas afirmaciones, que los elementos esenciales del contrato de trabajo contemporáneo, no son una realidad emergente ex novo del siglo XX, sino que, más bien, hunde sus raíces, aunque con las reservas conceptuales y metodológicas necesarias, en el derecho histórico de los reinos de España.

Y para ello, el Dr. D. Miguel Ángel Chamocho Cantudo, autor de la obra, y profesor de Historia del Derecho de la Universidad de Jaén, inaugura su estudio con una frase del laboralista Pérez Botija, que no sólo inspira este estudio, sino que además envuelve de principio a fin el objetivo metodológico y científico del autor. Y es que, como el autor irá 
mostrando a cada una de sus páginas, las conquistas que en Europa se han logrado por huelgas, revoluciones y miedos para los trabajadores de las sociedades contemporáneas, ya se encontraban recogidas jurídicamente para regular el trabajo de los indios de América con ocasión de la colonización española, tal y como afirmaba Pérez Botija en su Curso de Derecho del Trabajo.

¿Cuál ha sido la pretensión metodológica del autor para poder, de alguna manera, demostrar la veracidad de las palabras del profesor Pérez Botija? El Dr. Chamocho ha partido de lo que la tradición historiográfica laboralista ha articulado como los elementos esenciales que, con ocasión de la revolución industrial, y el intervencionismo de los estados europeos en la regulación de las relaciones de trabajo, han configurado las relaciones contractuales de trabajo: libertad, ajenidad, dependencia y salario. Estos cuatro elementos comenzarán a generalizarse a comienzos del siglo XX, en el nacimiento de los contratos de trabajo (Código de Trabajo francés de 1910 o Código de Trabajo español de 1926). El Dr. Chamocho vehicula su obra en la verificación jurídica, doctrinal y documental de que dichos cuatro elementos fueron reconocidos por las autoridades soberanas españolas a los naturales de las Indias occidentales. Así, en el capítulo primero (pp. 43-105) reconstruye la concepción jurídica de la condición de hombres libres a los naturales de las Indias, vasallos de Castilla y, por ende, sometidos a la misma disciplina social que los demás vasallos de la metrópolis española: los naturales de las Indias son libres, pero por sus especiales circunstancias sociales, fueron catalogados jurídicamente bajo la concepción de personas miserables a los que habría que legislar para dotarles de una especial protección jurídica y social. Un favor protectionis del Estado que fermentará una legislación social protectora sin parangón, y que avanzará muchos siglos en el tiempo, algunas de las conquistas sociales de las revoluciones contemporáneas: jornada laboral, garantías salariales, protección del embarazo, derechos sociales, etc., pero vayamos por partes.

Sin perjuicio del importante volumen de cédulas reales emanadas de la cancillería española garantistas de la libertad de los naturales de las Indias, recogidas por el Dr. Chamocho en su primer capítulo, no es menos cierto que, los españoles colonizadores explotaron y compelieron a un trabajo compulsivo a los indios. No debemos olvidar que la sociedad española que se asienta en las Indias a finales del siglo XV y comienzos del siglo XVI, es una sociedad desigual por naturaleza, basada en el privilegio jurídico, que exporta a aquellas tierras instituciones feudales basadas en el trabajo obligatorio, tales como los repartimientos o las encomiendas. Sumémosle a esta realidad, aquella otra que permitió a los españoles asumir en su propio beneficio, ciertas instituciones precolombinas por las que los imperios, como el inca, ya explotaban compulsivamente el trabajo de forma obligatoria para con sus naturales, como era el caso de la mita incaica, o la institución social del yanaconazgo, tal y como muestra el autor en su capítulo segundo (pp. 107-142).

El capítulo tercero (pp. 143-188) reconstruye los elementos esenciales del contrato por el que los indios prestan el trabajo a los españoles. Y las conclusiones son obvias: si los indios naturales de las Indias fueron considerados súbditos de Castilla, y vasallos de los soberanos españoles, la regulación jurídica del trabajo no podía ser diferente 
de la establecida para los naturales de Castilla. De ahí que la capacidad contractual, la duración del contrato, la jornada de trabajo y el establecimiento de las reglas garantistas para la efectiva materialización del trabajo, apenas difieren de las ya existentes para Castilla, siempre bajo la concepción feudal que impera en aquel modelo social europeo.

Ahora bien, los elementos diferenciadores, como ya indicara el Dr. Chamocho en su trabajo, se encuentran en las palabras de Pérez Botija, y hemos de encontrarlos en el ciclo heteronómico propuesto por el Estado español, a través de un volumen de cédulas reales protectoras para los naturales de las Indias, no sólo de la relación el trabajo, sino vestigios de una incipiente seguridad social, desconocida para el feudalismo occidental europeo. Se entrelazan ahora la consideración de los naturales de las Indias como personae miserabilis, necesitadas de un favor protectionis del Estado español, que se reconstruye a partir de un ciclo heteronómico proteccionista de la salud y la seguridad en el trabajo de los naturales de las Indias (pp. 176-188).

Así, por ejemplo, en materia de salarios, el pago obligatorio no sólo de las horas de trabajo efectivas, sino el salario in itinere a los naturales de las Indias, no reconocido siquiera para los trabajadores de la metrópoli.

En materia de reconocimiento del derecho social a la maternidad, ya desde las Leyes de Burgos de 1512-1513, estaba reconocida la protección, al menos durante cuatro meses del embarazo, prohibiendo así el trabajo en las minas para estas mujeres.

En materia de seguridad y protección de la salud de los trabajadores indianos en el oficio de portear cargas, desde los puertos y astilleros hasta las granjerías en el interior de las islas o continente, dicho porteo estuvo plagado de normas protectoras, que evidenciaban las constantes denuncias por los riesgos a la salud que conllevaba, y regulaban el peso y la distancia del porteo, exigiendo siempre que fuera posible el uso de animales de carga.

En materia de previsión social, otro buen volumen de normas es recogido por el Dr. Chamocho, tales como las dirigidas a la curación de los enfermos, sobre todo de los trabajadores en las minas, la facilitación de medicinas y hospitalización corriendo a cargo los gastos de los empleadores, construcción de hospitales o casas-hospitales en las reducciones de indios, como política social emblemática y pilar del Estado español en las Indias, etc.

Por último, un cuarto capítulo (pp. 189-233) permite al autor reconstruir, ahora desde el oficio propio del historiador del derecho, la modalidad contractual, desde el viejo derecho romano justinianeo hasta la legislación indiana, la modalidad contractual que regula el trabajo de los indios. Desde la vieja locatio conductio operarum romana, pasando por el operatiorum conducticiorum, recogido por algunos fueros municipales, como el de Cuenca, y que evidencia la recepción del derecho justinianeo, más visible en el Código de las Siete Partidas, a través del contrato de arrendamiento o alogamiento. Igualmente, el Dr. Chamocho sigue la trayectoria de esta modalidad contractual en el derecho de las Cortes de Castilla y otras tantas normas recopiladas, para finalmente desembarcar en el Derecho de las Indias. Es, en este sentido, particular la conclusión propuesta por el autor en la evolución del lenguaje jurídico que 
caracteriza esta modalidad contractual, dado que, como indica el autor, la transmisión de la nomenclatura jurídica, margina la tradición justinianea recibida en Partidas -la modalidad de la locatio, de logarse o alogarse-, por la de alquilarse o arrendarse por un jornal, como recoge luego la tradición jurídica de las Cortes españolas y leyes recopiladas. Versión ésta, la de alquilarse por un jornal que es la exportada a las Indias occidentales, en sus formatos particulares y específicos de concierto o asiento.

Acaso, como bien indica el Dr. Chamocho en las salvedades metodológicas propuestas en su introducción, ¿el hecho de que los españoles obviaran, en muchas ocasiones, el cumplimiento de estas normas del Estado protectoras del trabajo de los naturales de las Indias, exigiendo una compulsividad en el trabajo que minimizara los logros sociales, es condición sine qua non para negar la existencia, y en cierta medida, eficacia de dichas normas sociales protectoras del trabajo? Es evidente que eso sería como afirmar que todas las vulneraciones de las normas de protección social de los trabajadores actuales por parte de empresarios o empleadores, negaran la sustancia sistémica de dicha protección social.

Un elenco documental y bibliográfico completan una obra que, efectivamente, puede mostrarnos a los laboralistas que existieron normas laborales más allá de la revolución industrial, y que quizá debiéramos de dirigir algunas de nuestras reflexiones intelectuales sobre períodos anteriores a los que tradicionalmente hemos considerado como los emergentes al nacimiento del moderno derecho del trabajo. Así, podríamos estar de acuerdo con las palabras de Pérez Botija, o con las utilizadas por el Dr. Chamocho para finalizar su obra, referentes al laboralista peruano, Jorge Montenegro Baca, quien afirmaba que el derecho del trabajo que los españoles dieron a los naturales de las Indias permitieron excelentes precedentes históricos de materialización jurídica de "justicia social y de la seguridad social".

Para concluir no puedo sino afirmar que esta obra, que ya ha sido objeto de un merecido galardón y cuya lectura recomiendo efusivamente, contribuirá a un mejor conocimiento de los antecedentes de la historia del Derecho del Trabajo y a tener una visión más exacta del régimen jurídico aplicable a las prestaciones de servicios de los naturales de las Indias bajo la vigencia de la legislación castellana. 